\title{
Synthesis, Characterization and Antibacterial Activity of Some Penicillin Derivatives
}

\author{
Asmaa A. Jawad ${ }^{1,2, *}$ and Ammar J. Alabdali ${ }^{2}$ \\ ${ }^{1}$ Forensic DNA Research and Training Center, Al-Nahrain University, Baghdad, Iraq \\ 2Department of Chemistry, College of Sciences, Al-Nahrain University, Baghdad, Iraq
}

\begin{tabular}{ll}
\hline \multicolumn{1}{c}{ Articles Information } & \multicolumn{1}{c}{ Abstract } \\
\hline Received: & This study illustrated the synthesis of two new di amidine compounds ([c] and \\
08.11 .2020 & [d]) by reaction of 6-amino penicillanic acid (6-APA) with di a-amino nitrile \\
Accepted: & compounds ([a] and [b]). [a] and [b] di a-amino nitrile compounds synthesized \\
23.11 .2020 & from the condensation reaction on aldehyd and di amine in the presence of \\
Published: & potassium cyanid as one pot three components reaction. The new di amidine \\
01.12 .2020 & compounds ([c] and [d]) have been proven their efficiency by inhibiting some \\
\hline Keywords: & types of bacteria (Staphylococcus aurous, Streptococcus, Escherichia coli and \\
Amidine & klebsiella). Amidine compound [d] showed better effect than [c] against the \\
6-amino penicillanic acid & selected bacteria. The synthesized compounds were characterized by \\
Alpha-amino nitrile & conventional techniques using infrared spectrophotometer (IR) and proton- \\
Penicillin derivatives & nuclear magnetic resonance (1H-NMR).
\end{tabular}

DOI: $10.22401 /$ ANJS.23.4.05

*Corresponding author: samaalkafaji@yahoo.com

\section{Introduction}

Amidine is an organic compounds have form $\mathrm{N}=\mathrm{C}-\mathrm{N}$ and considered to be analogue to carboxylic acid, ester or amide [1]. Amidine was first synthesized by Gerhardt by reacting $\mathrm{N}$-phenylbenzimidyl chloride and aniline in the nineteenth century [2]. Amidines enter various organic reactions to prepare different compounds, especially cyclic compounds [3], just like Schiff bases [4]. Amidines and bis amidine compounds are play an important role in treating many diseases and aliments, such as inflammatations [5] cancer [6] alzheimer's disease [7] parasites [8], and the most common application in the past was as anti-bacterial agent [9-12].

Amidines can be prepared in different ways using multiple chemicals [13-15], especially from nitrile compounds [16,17]. Penicillin is anti-bacterial agent, useful in treating some human diseases but is limited by the ability of some bacteria to acquire resistance to the drug. Therefore new derivatives are required, some researchers synthesize new organic compound or to control the resistance of bacteria. The interpretation of this work is to synthesize derivatives of penicillin with two beta-lactam groups to achieve the role of structure activityrelationship property [18].

\section{Experimental}

\section{Chemicals and Instruments}

All materials used in this study were provided and purchased from the original manufacturing places Aldrich,
Fluka and B.D.H. Infra-red spectra were recorded with FTIR BRUKER spectrophotometer and SHIMADZU spectrophotometer 8300 in wave number range of (4004000) $\mathrm{cm}^{-1}$ and ${ }^{1} \mathrm{H}-\mathrm{NMR}$ spectra were recorded on VARIAN $500 \mathrm{MHz}$ spectrometers using deuterated dimethyl sulfoxid (DMSO-d6) as solvent.

\section{Organic Syntheses}

Synthesis of a-amino nitrile compounds [a] and [b] [19]:

2 mmole of aldehyde (veratraldehyde or vanillin) was dissolved in $15 \mathrm{~mL}$ glacial acetic acid followed by the addition of 1 mmole of di-amine compound (benzidine). Small amount of $p$-toluene sulfonic acid was added to the reaction as catalyst with stirring to produce di imine compound, 4 mmole of $\mathrm{KCN}$ (excess) was added to the reaction after half hour and stirred for two days. The reaction mixture poured onto crashed ice and made slightly alkaline with ammonia solution addition, then left over night. The precipitate was filtered by Buchner funnel and washed with water to yield di- $\alpha$-amino nitrile compounds [a] and [b] respectively. Scheme 1 shows the reaction of aldehydes with amine compound in the presence of potassium cyanide. To diagnose the presence of the nitrile group chemically, small amount of [a] or [b] was heated with sodium hydroxide solution (10\%), the released ammonia gas was detected by wet red litmus paper that indicated the formation $\alpha$-amino nitrile compound. Table 1 included physical data of [a] and [b] $\alpha$-amino nitrile compounds. 


\title{
Al-Nahrain Journal of Science
}

ANJS, Vol.23 (4), December, 2020, pp. 29-34

\begin{abstract}
Synthesis of amidine compounds [c] and [d] [20]:
1 mmole of $\alpha$-amino nitrile [a] or [b] was dissolved in 15 $\mathrm{mL}$ absolute methanol and mixed with $5 \mathrm{~mL}$ sodium methoxide $(23 \mathrm{mg}$ sodium metal dissolved in $3 \mathrm{~mL}$ methanol). The mixture stirred for two hours, and then 2 mmole of 6-aminopenicillanic acid was added. The reaction mixture was refluxed for 8 hours. Amidine
\end{abstract}

compounds [c] and [d] were produced respectively. Scheme 1 shows the reaction of $\alpha$-amino nitrile compound with amine. Compounds [c] and [d] filtered and washed with water, then purified and crystallized by ethyl acetate/methanol solvents. Table 1 included physical data of [c] and [d] amidine compounds.

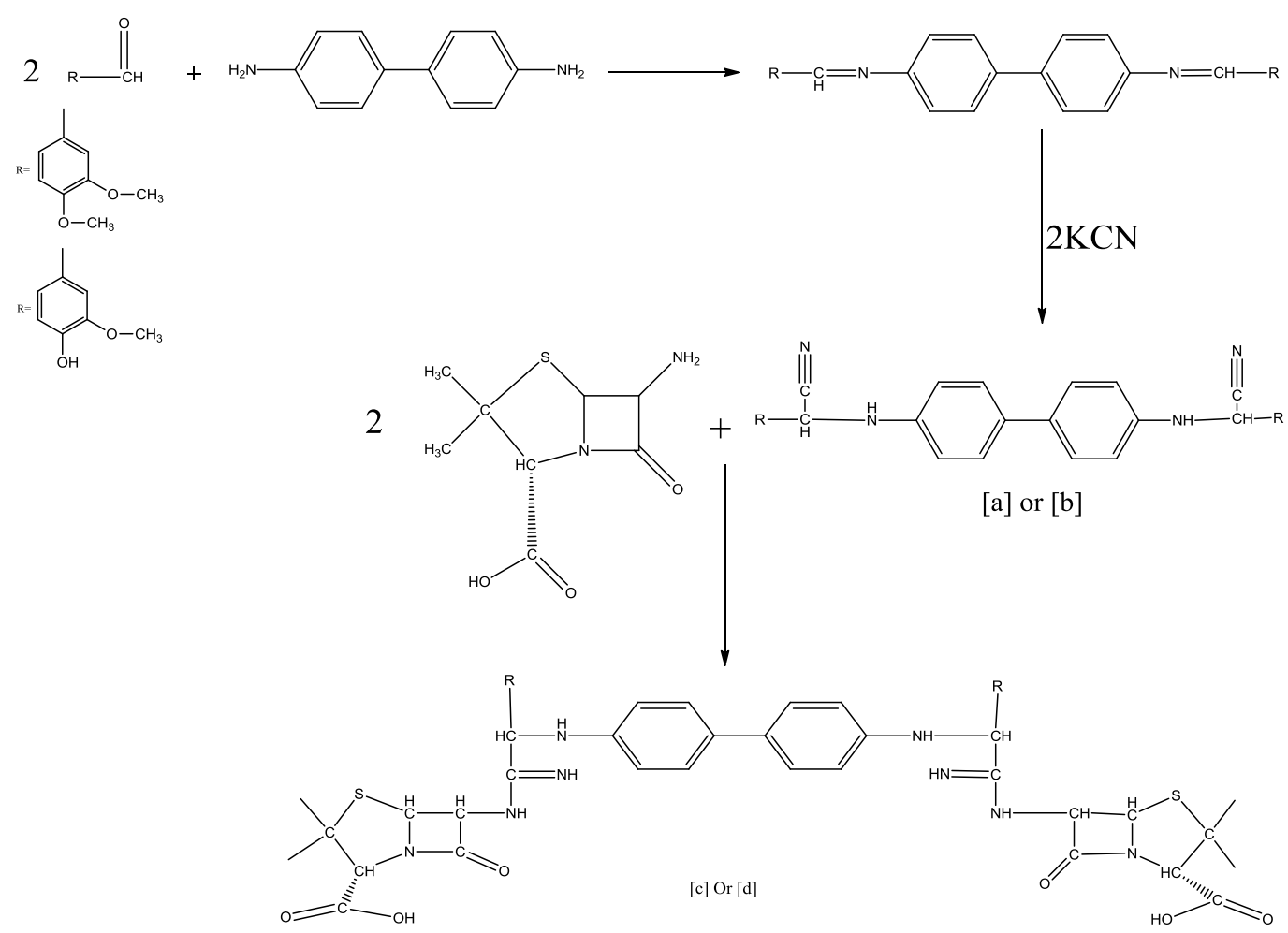

Sachem 1. The synthesis steps of [c] and [d] compounds.

Table 1. The physical properties of organic compounds.

\begin{tabular}{|c|c|c|c|c|c|}
\hline Symbol & Chemical formula & Molecular weight $\left(\right.$ g mole $^{-1}$ ) & Color & M.p ${ }^{\circ} \mathrm{C}$ & Yield \% \\
\hline [a] & $\mathrm{C}_{32} \mathrm{H}_{30} \mathrm{~N}_{4} \mathrm{O}_{4}$ & 534.23 & Yellow & $200-205$ & 88 \\
\hline [b] & $\mathrm{C}_{30} \mathrm{H}_{26} \mathrm{~N}_{4} \mathrm{O}_{4}$ & 506.2 & Red & $220-225$ & 80 \\
\hline [c] & $\mathrm{C}_{48} \mathrm{H}_{54} \mathrm{~N}_{8} \mathrm{O}_{10} \mathrm{~S}_{2}$ & 966.34 & Orange & $213-215$ & 77 \\
\hline [d] & $\mathrm{C}_{46} \mathrm{H}_{50} \mathrm{O}_{10} \mathrm{~S}_{2}$ & 954.34 & Brawn & $218-220$ & 70 \\
\hline
\end{tabular}

\section{Antimicrobial activity}

In this study, the desired products amidine compounds [c] and [d] were prepared and biological efficacy was tested against four types of bacteria, two are gram positive (Staphylococcus aurous and Streptococcus) and two are gram negative (Escherichia coli and Klebsiella) using the lowest concentration of the substances $10^{-3} \mathrm{M}$.

The antibacterial activities were evaluated using well diffusion method on Mueller-Hinton agar by working zones in millimeter $(\mathrm{mm})$ which filled with $100 \mu \mathrm{l}$ of the test samples and incubated at $37{ }^{\circ} \mathrm{C}$ for one day. After incubation, the diameter of the inhibition zones measured using a ruler. The area of inhibition is clear and surrounding the place of injection of the sample and bacterial not growth in it.

\section{Results and Discussion}

This study aims to synthesize new penicillin compounds of two symmetrical terminals possessing amidine and betalactam groups and study the behavior against different types of bacteria. The organic compounds that have been prepared have proven good efficacy against the types of bacteria used in order to contain two effective groups of beta-lactams with addition to the final formulation of amidine $(\mathrm{N}=\mathrm{C}-\mathrm{N})$, which has previously proven effective as an anti-bacterial so, expected that the synthesized compounds are promising as antibiotic compounds in the pharmaceutical field against different kinds of bacteria and especially for the resistant type. 


\title{
Al-Nahrain Journal of Science
}

ANJS, Vol.23 (4), December, 2020, pp. 29-34

\begin{abstract}
Infra-red spectroscopy
The absorption bands of infrared spectra of [a] and [b] showed peaks at $2228 \mathrm{~cm}^{-1}$ and $2235 \mathrm{~cm}^{-1}$ respectively which could be attributed to nitrile group that generally appeared some times as a weak peak at range (2250-2200) $\mathrm{cm}^{-1}[21,22]$. This supported by chemical test mentioned previously in the experimental. The reaction of [a] or [b] with 6-APA to produce [c] and [d] must involve disappearing of nitrile group and forming amidine group instead. The absorption bands of infrared spectrum of [c] and [d] showed new peaks at $1633 \mathrm{~cm}^{-1}$ and 1614
\end{abstract}

respectively which represented $(\mathrm{N}=\mathrm{C}-\mathrm{N})$ starching that normally presented near this area $[20,23,24]$. The attached 6-APA part showed characteristic peaks of carboxylic carbonyl $(\mathrm{COOH})$ and beta-lactam carbonyl $(\mathrm{C}=\mathrm{O})$ that occurred at $1670 \mathrm{~cm}^{-1}$ and $1730 \mathrm{~cm}^{-1}$ for [c] and [d] respectively. Hydroxyl group in [c] and [d] appeared as broad peak between $3300-3500 \mathrm{~cm}^{-1}$ [22]. Table 2 shows the characteristic absorption bands of [a], [b], [c] and [d] compounds.

Table 2. The most important absorption bands of the organic compounds.

\begin{tabular}{|c|c|c|c|c|c|c|c|c|}
\hline Compound & $\mathbf{O - H}$ & $\mathbf{v N}-\mathbf{H}$ & $\mathbf{v C} \equiv \mathbf{N}$ & $\begin{array}{c}\mathbf{v C}=\mathbf{O} \\
\text { carboxylic }\end{array}$ & $\begin{array}{c}\mathbf{v C}=\mathbf{O} \\
\boldsymbol{\beta} \text {-lactam }\end{array}$ & $\begin{array}{c}\mathbf{v N = C}-\mathbf{N} \\
\text { Amidine }\end{array}$ & $\begin{array}{c}\boldsymbol{\delta} \mathbf{N}-\mathbf{H} \\
\text { Binding }\end{array}$ & $\begin{array}{c}\mathbf{C}=\mathbf{C} \\
\text { Aromatic }\end{array}$ \\
\hline$[\mathrm{a}]$ & - & 3355 & 2228 & - & - & - & 1610 & 1503,1430 \\
\hline$[\mathrm{c}]$ & - & 3355 & - & 1672 & 1733 & 1630 & 1609 & 1585 \\
\hline$[\mathrm{b}]$ & 3364 & 3220 & 2235 & - & - & - & 1609 & 1510,1447 \\
\hline$[\mathrm{d}]$ & 3504 & 3352 & - & 1670 & 1730 & 1614 & - & 1597 \\
\hline
\end{tabular}

\section{Proton nuclear magnetic resonance}

Proton nuclear magnetic resonance ${ }^{1} \mathrm{HNMR}$ was used for the characterization of the newly synthesized amidine compound. ${ }^{1} \mathrm{HNMR}$ spectra were used to confirm the final structure of compounds.

\section{${ }^{1} \mathrm{H}-\mathrm{NMR}$ amidine compound}

The ${ }^{1} \mathrm{H}-\mathrm{NMR}$ spectrum of amidine compound [c], Figures 1 showed singlet signal near (1.4) ppm which could be attributed to methyl groups which appeared at range (12.5) ppm rang $[25,26]$. Dihydrothiazine ring (-SH-C-) signal appeared at (3.2) ppm which generally noticed at range (3-3.6) ppm [26]. Amine group $(\mathrm{N}-\mathrm{H})$ which occurred at rang (3-5) ppm normally [22].
Three peaks appeared as doublet for $\beta$-lactam ring were observed around (4.2-4.4) ppm could be attributed to $(\mathrm{CH}-\mathrm{CH}),(\mathrm{CO}-\mathrm{CH})$ and $(\mathrm{N}-\mathrm{CH})$ which appeared at range (4-4.9) [26]. New peaks appeared at (10.5-10.6) ppm which attributed to hydroxyl $(\mathrm{O}-\mathrm{H})$ of carboxylic acid which generally fixed at range (10.5-12) ppm rang [22]. Amidine group $(-\mathrm{HN}-\mathrm{CH}=\mathrm{NH})$ appeared as singlet signal in two different locations this is because the double bond was in delocalization forms, so one peak attributed to (-NH-C-) form, which appeared at range (1.3-2.8) ppm, while the other peak could be attributed to $(\mathrm{NH}=\mathrm{C}-)$ form, which appeared at range (4-7) ppm [24]. 


\section{Al-Nahrain Journal of Science}

ANJS, Vol.23 (4), December, 2020, pp. 29-34

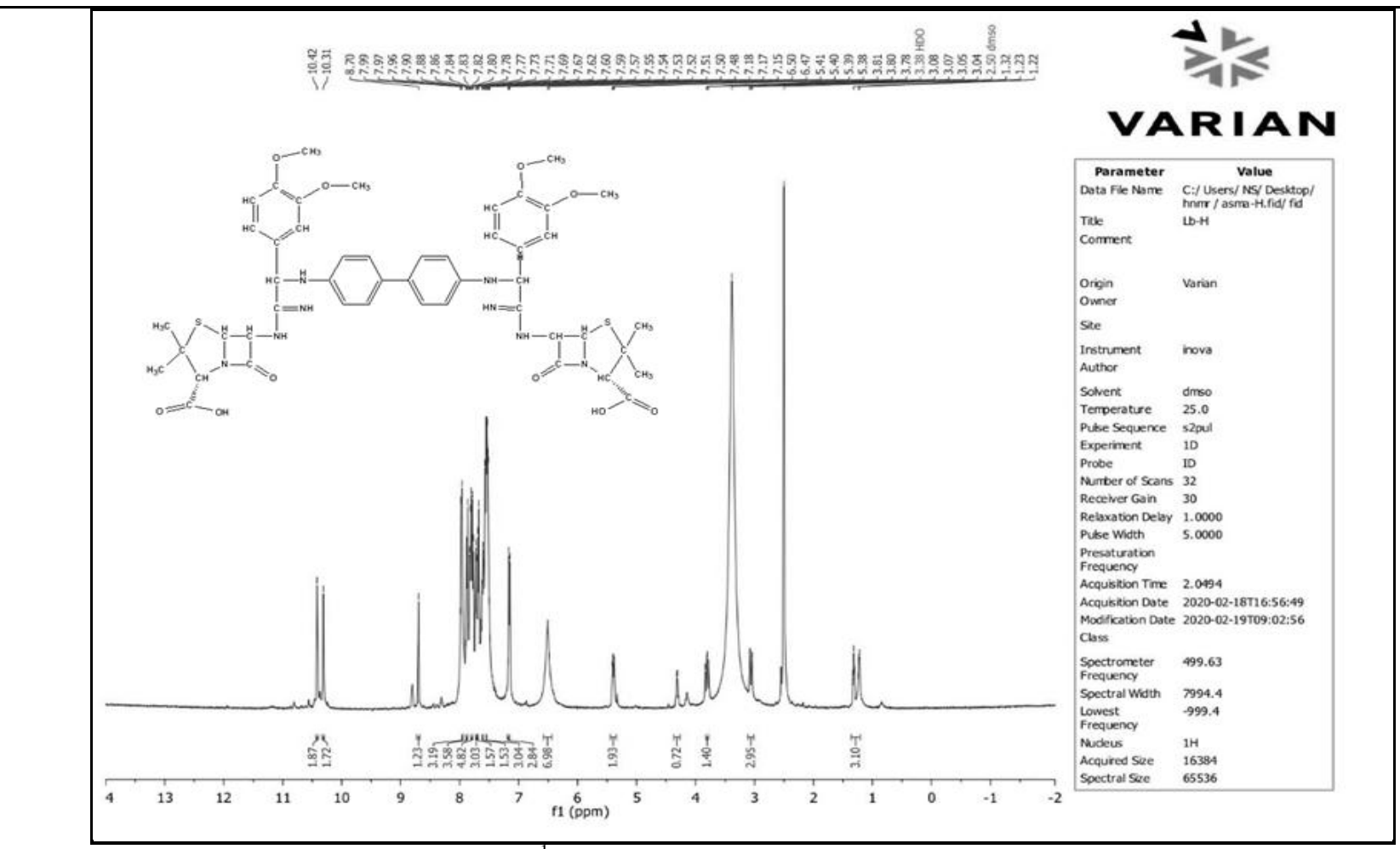

Figure 1. ${ }^{1}$ HNMR spectrum of amidine compound [c].

\section{Biological study}

In our study, compounds [c] and [d] were evaluated in vitro against four types of bacteria, two of grams positive (Staphylococcus aurous and Streptococcus) and two of grams negative (Escherichia coli and Klebsiella). using well diffusion method and follow the amount of inhibition of these ligands through the use of the least concentration of the inhibitor. The compounds appeared good results, due to the fact that compounds contained two antibacterial groups which are amidine [27] and beta-lactam groups [28] postulated in two terminals. Figure 2 shows the inhibition zones of [c] and [d] on agar culture. Table 3 shows the inhibition zones of the prepared compounds against bacteria.

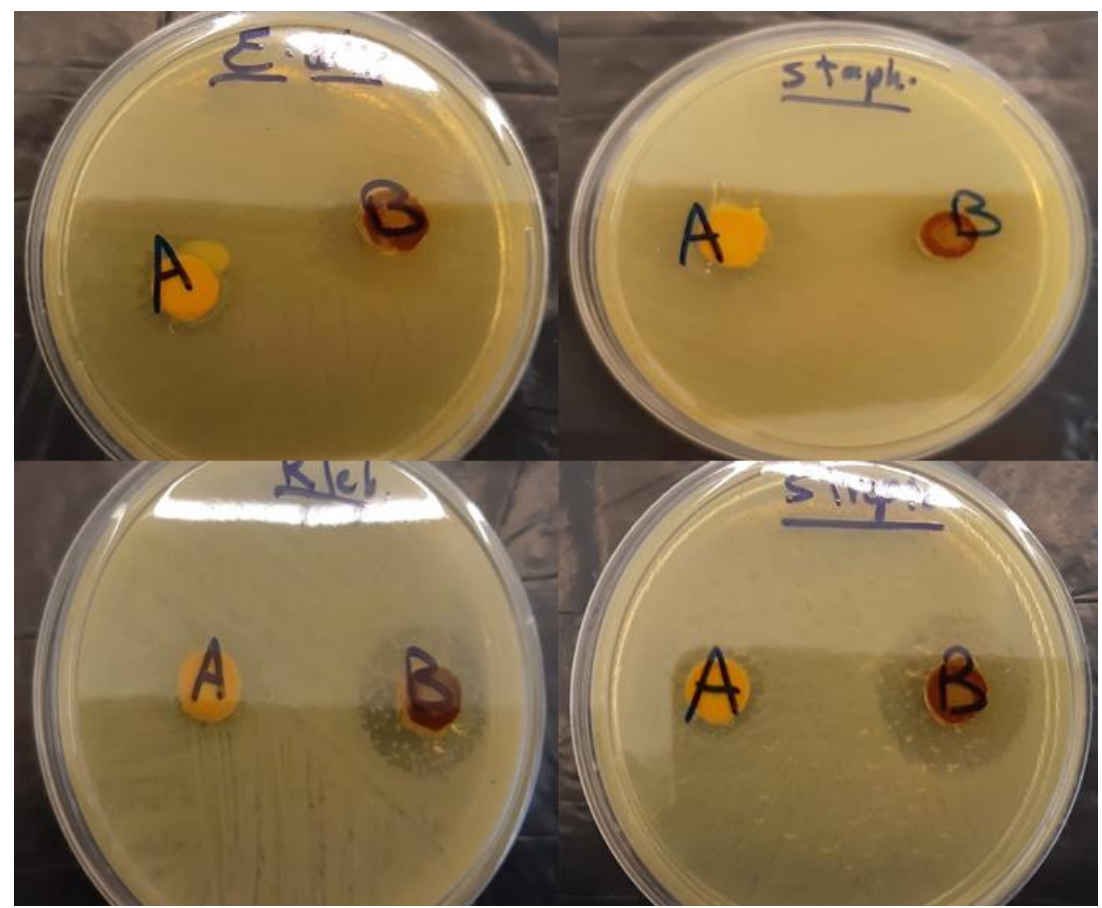

Figure 2. The inhibition zones of [c] and [d]compounds against bacteria. 


\section{Al-Nahrain Journal of Science}

ANJS, Vol.23 (4), December, 2020, pp. 29-34

Table 3. The inhibition zone of [c] and [d]compounds against bacteria.

\begin{tabular}{|c|c|c|c|c|}
\hline \multicolumn{5}{|c|}{ Inhibition zone (mm) } \\
\hline Compounds & Escherichia coli & Klebsiella & Staphylococcus aurous & Streptococcus \\
\hline$[\mathrm{c}]$ & 11 & 10 & 10 & 12 \\
\hline$[\mathrm{d}]$ & 18 & 20 & 11 & 20 \\
\hline
\end{tabular}

\section{Conclusion}

Compounds [c] and [d] were evaluated in vitro against four types of bacteria, and showed good efficacy by inhibiting bacteria diffusion, due to the presence of two well known beta-lactam groups as anti bacterial, in addition to the presences of two amidine groups. Eventually, novel compound structures achieved, having powerful structure-activity relationship property. This is in the interest of fighting drug-resistance bacteria. Amidine compound [d] showed better effect than [c] against the selected bacteria. the presence of hydroxyl group (i.e. [d]) instead of methoxy group (i.e. [c]) could be play role in the structure-activity relationship, that it form hydrogen bonding which could assisted in the interaction toward bacteria.

\section{Acknowledgement}

A special thank goes to Department of Chemistry, College of Science, Al-Nahrain University for their outstanding assistance to perform this research.

\section{References}

[1] Patai, S., "Chemistry of amidines and imidates"; Wiley, New York, 1975.

[2] Andrew, C. J., "Some aspects of organonitrogen transition metal complexes"; Diss. Durham University, 1982.

[3] Okuda, K.; Ide, R.; Uramaru, N.; Hirota, T., "Polycyclic N-Heterocyclic Compounds. Part 84: Reaction of $\mathrm{N}$-(pyrido [3', 2': 4, 5] thieno [3, 2-d] pyrimidin-4-yl) amidines or $\mathrm{N}$-(pyrido $\left[2^{\prime}, 3^{\prime}: 4,5\right]$ furo [3, 2-d] pyrimidin-4-yl) amidines with Hydroxylamine Hydrochloride"; J. Heterocycl. Chem, 52, 880-887, 2015.

[4] Al-Juburi, R. M., "Synthesis and Characterization of Some Heterocyclic Compounds (Oxazepine, Tetrazole) Derived from Schiff Bases"; ANJS, 15, 60-67, 2012.

[5] Lonez, C.; Legat, A.; Vandenbranden, M.; Ruysschaert, J. M., "DiC14-amidine confers new antiinflammatory properties to phospholipids"; Cell. Mol. Life Sci, 65, 620, 2008.

[6] Aryaa, S.; Kumar, N.; Roy, P.; Sondhi, S. M., "Synthesis of amidine and bis amidine derivatives and their evaluation for anti-inflammatory and anticancer activity"; Eur. J. Med. Chem, 59, 7-14,2013.

[7] Oehlrich, D.; Prokopcov, H.; Gijsen, H. J. M., "The evolution of amidine-based brain penetrant BACE1 inhibitors, Bioorganic Med"; Chem. Lett, 24, 20332045, 2014.
[8] Farahat, A. A.; Ismail, M. A.; Kumar, A.; Wenzlerde, T.; Brun, R.; Paul, A.; Wilson, W. D.; Boykin, D. W., "Indole and benzimidazole bichalcophenes: Synthesis, DNA binding and antiparasitic activityEur"; J. Med. Chem., 143,1590-1596, 2018.

[9] Nakamura, S. H.; Umezawa. H., "The Structure of Bottromycin A, a New Component of Bottromycinsl; Chem. Pharm. Bull, 14, 981-986, 1966.

[10] da Silva, C. F.; Batista, M. M.; Batista, D. G. J., "In vitro and in vivo studies of the trypanocidal activity of a diarylthiophene diamidine against Trypanosoma cruzi"; Antimicrob. Agents. Chemother, 52, 33073314, 2008

[11] Özden, S.; Atabey, D.; Yıldız. S.; Göker. H., "Synthesis and potent antimicrobial activity of some novel methyl or ethyl 1H-benzimidazole-5carboxylates derivatives carrying amide or amidine groups"; Bioorg. Med. Chem, 13, 1587-1597, 2005.

[12] Korbad.; Balaji, L.; Sang-Hyeup, L., "Simple and efficient procedure for synthesis of N'-arylamidines using trimethylaluminum, Bulletin of the Korean Chemical Society, 34, 1266-1668,2013.

[13] Chavana, N. L.; Naika, N. H.; Nayakb, S. K.; Kusurkar, R. S., "An efficient route towards the synthesis of monosubstituted $\mathrm{N}$-aryl amidines from 4, 5-dihydro-1, 2, 4-oxadiazoles"; Arkivoc, 2, 248-255, 2010.

[14] Obenauf, J.; Kretschmer, W. P.; Bauer, T.; Kempe, R. H., "An Efficient Titanium Amidinate Catalyzed Version of Ziegler's Aufbaureaktion"; Eur. J. Inorg, Chem, 2013, 537-544, 2013.

[15] Kulangiappar, K.;Anbukulandainathan, M.; Raju, T., "Synthetic communications: an international journal for rapid communication of synthetic organic chemistry; Synth. Commun, 1, 2494-2502, 2014.

[16] Wang, J.; Xu, F.; Cai, T.; Shen, Q., "Addition of amines to nitriles catalyzed by ytterbium amides: An efficient one-step synthesis of monosubstituted $\mathrm{N}$ arylamidines"; Org. Lett, 10,445-448, 2008.

[17] Khalifa, M. M.; Bodner, M. J.; Berglund, J. A.; Haley, M. M., "Synthesis of N-substituted aryl amidines by strong base activation of amines"; Tetrahedron letters, 56, 4109-4111, 2015.

[18] Janusz, K. W.; Urbanczyk-lipkowska, Z. O. F. I. A.; Gluzinski, P., "The X-Ray Structural Investigation of 6-(N, N-1, 6-Hexyleneformamidine)-Penicillanic Acid (Mecillinam); J. Antibiot, 34, 282-287, 1981.

[19] Al-Ubaydi, A. Ph.D. Thesis, University of Baghdad, 1996.

[20] Arya, S.; Kumar, N., Roy, P.; Sondhi, S. M., "Synthesis of amidine and bis amidine derivatives 


\section{Al-Nahrain Journal of Science}

ANJS, Vol.23 (4), December, 2020, pp. 29-34

and their evaluation for anti-inflammatory and anticancer activity; Eur. J. Med. Chem, 59, 7-14, 2013.

[21] Mansoor, S. S.; Aswin, K.; Logaiya, K., "An efficient one-pot three-component synthesis of $\alpha$-amino nitriles via Strecker reaction catalysed by bismuth (III) nitrate; J. Saudi Chem. Soc, 20, S202-S210, 2016.

[22] Pavia, D. L.; Lampman, G.M.; Kriz, G. S.; Vyvyan, J. A., "Introduction to spectroscopy"; Engage Learning, 2008.

[23] Shainyan, B. A.; Meshcheryakov, V. I.; Sterkhova, I. V., "A convenient synthesis and structure of $\mathrm{N}$ trifluoromethylsulfonylamidines"; Tetrahedron, 71, 7906-7910, 2015.

[24] Patil, U. D.; Mahulikar, P. P., "A convenient, $\mathrm{TiCl}_{4} / \mathrm{SnCl}_{4}$-mediated synthesis of $\mathrm{N}$-phenyl or $\mathrm{N}$ aryl benzamidines and N-phenylpicolinamidines"; ISRN organic chemistry, 2012, 6, 2012.

[25] Ulrike, H., "NMR spectroscopy in pharmaceutical analysis"; Elsevier, 2017.

[26] Al-Noor, T. H.; Aziz, M. R.; AL-Jeboori, A.T., "Synthesis, characterization and antimicrobial activities of [Fe (II), Co (II), Ni (II), Cu (II) and $\mathrm{Zn}$ (II)] mixed ligand complexes Schiff base derived from amoxicillin drug and 4-(dimethylamino) benzaldehyde with nicotinamide"; J. chem. phar, 6, 1225-1231, 2014.

[27] Lanteri, C. A.; Trumpower, B. L.; Tidwell, R. R., "DB75, a novel trypanocidal agent, disrupts mitochondrial function in Saccharomyces cerevisiae, Antimicrob"; Agents Chemother, 48, 3968-3974, 2004.

[28] Alabdali, A. J.; Sabah, Y. H., "Synthesis, Characterization and Biological Evaluation of Penicillin Derivatives Complexes with Some Transition Metal Ions; Int. J. Curr. Microbiol. App. Sci, 5, 321-332, 2016. 